JOURNAL

of Health Inequalities

\title{
Evaluation of the prevalence and risk factors of pelvic floor disorders among women in rural Turkey
}

\author{
Selçuk Kaplan' ${ }^{1}$ Can Türkler², Mehmet Bülbül' ${ }^{1}$ Pınar Kırıcl ${ }^{1}$ \\ 'Department of Gynecology and Obstetrics, Adıyaman Univercity School of Medicine, Adıyaman, Turkey \\ ${ }^{2}$ Department of Gynecology and Obstetrics, Erzincan Binali Yıldırım University School of Medicine, Erzincan, Turkey
}

\begin{abstract}
Introduction: Pelvic floor disorders (PFD) are an important cause of urogynecological surgery affecting the quality of life seen in many women, such as pelvic organ prolapse (POP), stress urinary incontinence (SUI) and urge urinary incontinance (UUI). We aimed to determine prevalence and associated risk factors for SUI, UUI and POP in rural Turkey.

Material and methods: PFD approved for screening in Turkey in terms of screening questions and PFD was made using data obtained from the database. The patients were divided into three groups: patients with POP, SUI, and UUI. Of the patients, 7163 (43.9\%) were in the POP group, 6815 (41.8\%) were in the SUI group, and 2349 (14.3\%) were in the UUI group. The relationship between the frequency of symptoms commonly reported for SUI, UUI and POP and the relationship between demographic and pregnancy history information were compared.

Results: The prevalence of SUI was $37.8 \%$ (95\% CI: 37.3-38.2), 14.8\% (95\% CI: 14.3-15.3) for UUI and $43.8 \%$ (95\% CI: 43.2-44.5) for POP. In the multivariate binary logistic regression analysis, the risk of PFD increased with age, an increase in the number of vaginal births, high BMI, macrosomia, early maternal age, previous abdominal/pelvic surgery history, and difficult delivery history.

Conclusions: PFD are quite common among women in rural Turkey. However, risk factors are similar to risk factors in developed countries.
\end{abstract}

KEY WORDS: pelvic floor disorders, urinary stress incontinence, urinary urge incontinence, pelvic organ prolapse, risk factors.

ADDRESS FOR CORRESPONDENCE: Selçuk Kaplan, Department of Gynecology and Obstetrics, Adıyaman University School of Medicine, Atatürk Blv. No: 411, 02200 Merkez/Adıyaman, Tel: +90-416-223 38 00, Fax: +90-416 22338 36,

e-Mail: kaplan_2384@hotmail.com

\section{INTRODUCTION}

Pelvic floor disoders (PFD) are an important cause of urogynecological surgery affecting the quality of life seen in many women, such as pelvic organ prolapse (POP), stress urinary incontinence (SUI) and urge urinary incontinance (UUI) [1].

The combination of anatomical, physiological, genetic, lifestyle and reproductive factors are important factors affecting the risk of developing pelvic floor disorder. Pelvic floor functions decrease in women due to pregnancy and delivery. Pelvic floor disorder may develop due to reasons such as lifestyle, smoking, obesity and chronic intrabdominal pressure increase after this decrease. While most women become symptomatic in a few decades, they can develop early in women with risk factors and affect quality of life [2].

The most frequently stated risk factor for the development of PFD is vaginal delivery [3-6]. The use of forceps in vaginal deliveries and difficult birth also affect the development of PFD after this vaginal delivery $[7,8]$. Other obstetric risk factors include delivery of an infant with macrosomia (>4000 g), prolonged delivery and 
overweight body mass index (BMI) $[4,6,9]$. We aimed to determine prevalence and associated risk factors for stress urinary incontinence SUI, UUI and POP in rural Turkey.

\section{MATERIAL AND METHODS STUDY POPULATION}

This study is a cross-sectional study using the data recorded in the database of the hospital, the written data in the files and the results of the questionnaire with the patients who applied to the gynecology outpatient clinic of Adıyaman Training and Research Hospital between January 2017 and December 2019. Local ethics committee approval was received for the study committee (date: 1.06.2020, Ethics committee no: 2020/6-22).The study was carried out in accordance with the Helsinki Declaration Principles.

Among 145017 patients admitted to the outpatient clinic, 33094 patients with SUI, UUI and POP pre-diagnosis and/or diagnosis were identified. 14302 patients who did not come to follow-up and control of these patients and whose tests and imaging methods were not completed were excluded from the study. Of the remaining patients, 1206 patients did not agree to interview and participate in the study. 1259 patients had comorbidity of confirmed SUI and POP diagnosis. For this reason, they were excluded. The total number of patients diagnosed with SUI, UUI and POP and included in the study was 16327 (Fig. 1).

Exclusion criteria were a history of recurrent cesarean section, neurological disease (demyelinating diseases such as epilepsy, multiple sclerosis, etc.) and related treatment history, a history of neuropsychiatric drug use, history of known urogynecological surgery and diabetes mellitus.

\section{COLLECTION AND ANALYSIS OF DATA}

16327 patients were questioned by trained nurses and midwives. Interviews were made face to face or by phone. The patients were informed that these data would be used for the study and their consent was obtained.

The patients were divided into three groups. Patients with pelvic organ prolapse (POP), Stress Urinary Incontinance (SUI), and Urge Urinary Incontinance (UUI). Of the patients, 7163 (43.9\%) were in the POP group, 6815 (41.8\%) were in the SUI group, and 2349 (14.3\%) were in the UUI group.

Patients' age, working status, obstetric data (parity, maternal birth age, forceps/vacuum use in delivery actions or prolonged delivery history, fetal birth weights), pelvic surgery history (myomectomy, cystectomy, minimally invasive surgeries (hysteroscopy, laparoscopic surgery etc.). BMI classifications are classified as normal (18.5-24.99), overweight (25-29.99) and obese (>30) [10]. When the cases were first admitted to the outpatient clinic, they were distinguished by the following questions and the following two questions used in previous study models. This information was taken from the database, but was also distinguished by the same two questions in face-to-face interviews $[11,12]$. SUI: Do you typically lose your urine during sudden physical exertion, heavy lifting, coughing, or sneezing? UUI: Have you observed that there is a strong and sudden urge to urinate when you typically pass urine before reaching the toilet? POP was performed according to Pelvic Organ Prolapse Quantification System (POP-Q)

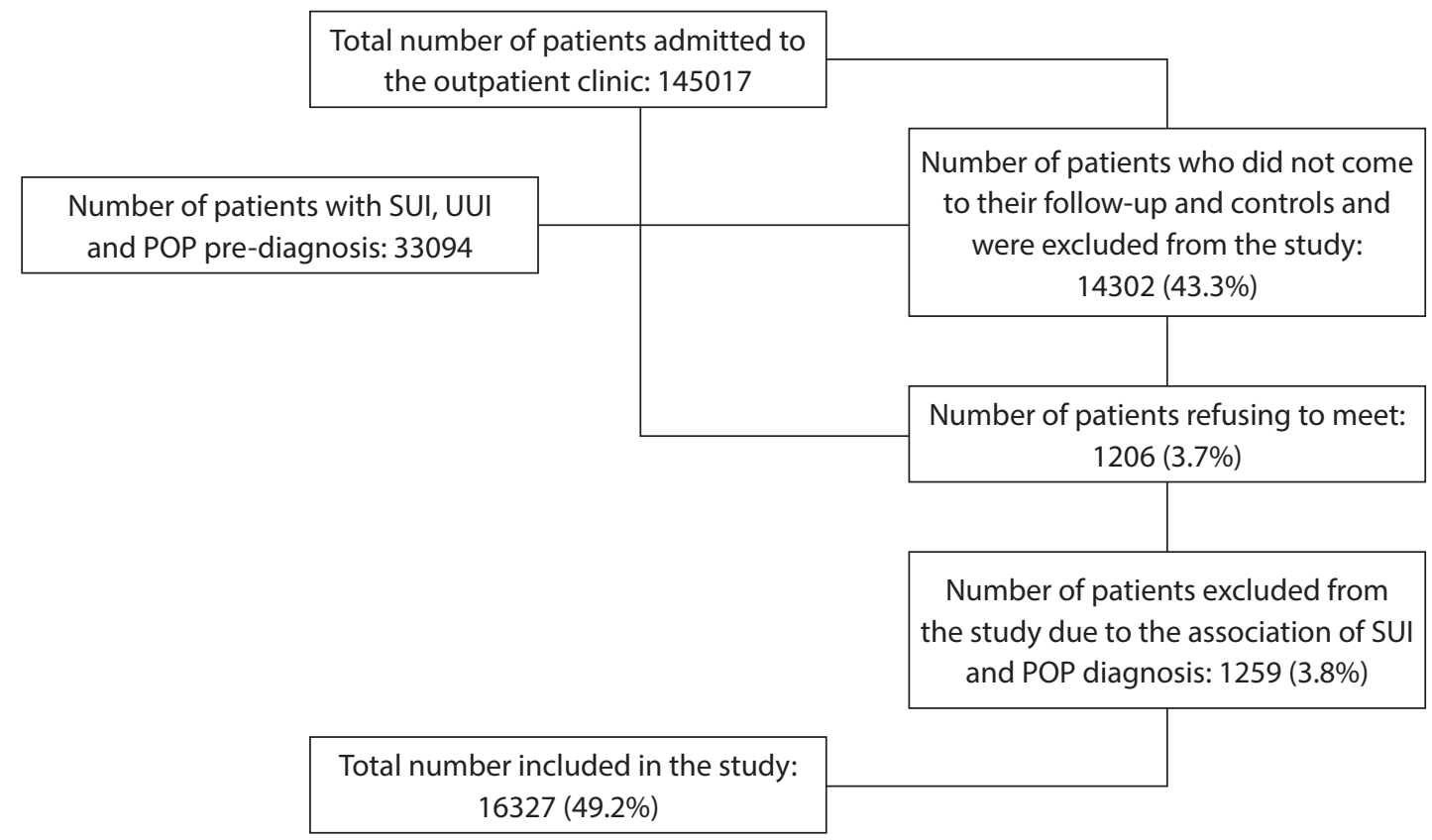

FIG. 1. Flow chart showing the patients screened for the diagnosis of pelvic floor disorder and their included in the analysis 
with examination and imaging in all patients, and the degree of POP in patients was between grade II-IV [13].

\section{STATISTICAL ANALYSIS}

Statistical analyzes were performed using SPSS 22 programme (International Business Machines Corp., Armonk, New York). Descriptive statistics are expressed as percentage with average counts for categorical data and as standard deviation for continuous data. Relation to results (SUI, UUI and POP) t-tests and chi-square tests for continuous data or Fisher's exact tests for categorical data were used. Binary and multivariate logistic regression models were used to investigate the impact of risk factors on SUI, UUI and POP. Odds ratio was specified with $95 \%$ confidence intervale; $p$ value $<0.05$ was considered statistically significant.

\section{RESULTS}

Data on the sociodemographic characteristics of the patients such as age, parity, education level, occupation and BMI are given in Table 1.

The prevalence of SUI was $37.8 \%$ (95\% CI: 37.3 38.2), $14.8 \%$ (95\% CI: $14.3-15.3$ ) for UUI and $43.8 \%$ (95\% CI: 43.2-44.5) for POP.
The risk of SUI had increased in women between the ages of 30-34 and 34-39 (OR: 1.99 [CI: 1.80-2.20]; $\mathrm{OR}_{1}: 1.49$ [CI: $\left.\left.1.39-1.61\right]\right)$, in 1-3 deliveries $\left(\mathrm{OR}_{1}: 1.13\right.$ [CI: 1.03-1.23]) and in women of 4 or more deliveries (multiparity) $\left(\mathrm{OR}_{1}: 1.12\right.$ [CI: 1.03-1.23]), in women with normal weight and over weight $\left(\mathrm{OR}_{1}: 1.20\right.$ [CI: 1.09-1.32], $\mathrm{OR}_{1}: 1.19$ [CI: 1.10-1.27]) and women with a macrosomic baby birth history $\left(\mathrm{OR}_{1}: 1.29\right.$ [CI: 1.21-1.37]). The risk of SUI decreased in women with a previous surgical history $\left(\mathrm{OR}_{1}: 0.31\right.$ [CI: $0.29-0.33$ ] $)$ and women with a difficult delivery history $\left(\mathrm{OR}_{1}: 0.65\right.$ [CI: 0.61-0.70]) (Table 2).

UUI risk was increased in women aged 50 and over $\left(\mathrm{OR}_{2}: 1.47\right.$ [CI: 1.34-1.60]), women with normal weight and over weight ( $\mathrm{OR}_{2}: 1.48$ [CI: 1.31-1.67], $\mathrm{OR}_{2}: 1.85$ [CI: 1.69-2.03]) and women with difficult delivery history $\left(\mathrm{OR}_{2}: 1.51\right.$ [CI: 1.37-1.66]). UUI risk was decreased in women with maternal age 30 and over $\left(\mathrm{OR}_{2}: 0.74\right.$ [CI: 0.52-1.05], $\mathrm{OR}_{2}: 0.70$ [CI: 0.62-0.78], OR : 0.15 [CI: 0.13$0.16])$, women without previous surgical history $\left(\mathrm{OR}_{2}\right.$ : 0.72 [CI: 0.66-0.79]) and obese women ( $\mathrm{OR}_{2}: 0.48$ [CI: 0.44-0.52]) (Table 2).

POP risk was increased in women aged 40 and over $\left(\mathrm{OR}_{3}: 2.33\right.$ [CI: 2.18-2.55], OR: 1.07 [CI: 1.01-1.15]), in

TABLE 1. Distribution of patient's age, parity, education level, occupation and body mass index data by groups

\begin{tabular}{|c|c|c|c|}
\hline Characteristics & SUI & UUI & POP \\
\hline \multicolumn{4}{|l|}{ Age } \\
\hline $30-34$ & $1424(20.9)$ & $221(9.4)$ & $553(7.7)$ \\
\hline $35-39$ & $1798(26.4)$ & 409 (17.4) & $1427(19.9)$ \\
\hline $40-49$ & $234(3.4)$ & $627(26.7)$ & $2357(32.9)$ \\
\hline$\geq 50$ & $3359(49.3)$ & $1092(46.5)$ & $2826(39.5)$ \\
\hline \multicolumn{4}{|l|}{ Parity } \\
\hline $0-3$ & $1074(15.8)$ & $337(14.3)$ & $1014(14.1)$ \\
\hline$\geq 4$ & $5741(84.2)$ & $2012(85.7)$ & $6149(85.9)$ \\
\hline \multicolumn{4}{|l|}{ Educational level } \\
\hline Lower secondary school & $3217(47.2)$ & $1491(63.5)$ & $4951(69.1)$ \\
\hline Secondary school and above & $1982(29.1)$ & $518(22)$ & $1304(18.2)$ \\
\hline Undergraduate & $1427(20.9)$ & $202(8.6)$ & $551(7.7)$ \\
\hline Graduate & $189(2.8)$ & $138(5.9)$ & $357(5)$ \\
\hline \multicolumn{4}{|l|}{ Occupation } \\
\hline Unemployed & $4916(72.1)$ & $1318(56.1)$ & $5082(71)$ \\
\hline Officer & $471(6.9)$ & $275(11.7)$ & $228(3.2)$ \\
\hline Worker & $1229(18.1)$ & $718(30.6)$ & $1759(24.6)$ \\
\hline Health employee & $199(2.9)$ & $37(1.6)$ & $94(1.2)$ \\
\hline \multicolumn{4}{|l|}{ BMI } \\
\hline $18.5-25$ & $937(13.7)$ & $391(16.7)$ & $719(10)$ \\
\hline $25-29.99$ & $1912(28.1)$ & 874 (37.2) & $1473(20.6)$ \\
\hline$\geq 30$ & 3966 (58.2) & $1084(46.1)$ & $4971(69.4)$ \\
\hline
\end{tabular}

SUI - stress urinary incontinance, $\mathrm{UUI}$ - urge urinary incontinance, $P O P$ - pelvic organ prolapse, $B M I$ - body mass index $\left(\mathrm{kg} / \mathrm{m}^{2}\right)$. Data are given as $n$ (\%) 
TABLE 2. Risk factors for pelvic floor disorders multivariate analysis results

\begin{tabular}{|c|c|c|c|c|c|c|c|c|c|}
\hline & SUI & UUI & POP & $\mathrm{OR}_{1}$ & $\mathrm{OR}_{2}$ & $\mathrm{OR}_{3}$ & $p_{1}$ & $p_{2}$ & $p_{3}$ \\
\hline \multicolumn{10}{|l|}{ Age, years } \\
\hline $30-34$ & 1024 & 221 & 553 & $1.99(1.80-2.20)$ & $0.74(0.52-1.05)$ & $0.53(0.47-0.59)$ & $<0.001$ & 0.008 & $<0.001$ \\
\hline $35-39$ & 1798 & 409 & 1427 & $1.49(1.39-1.61)$ & $0.70(0.62-0.78)$ & $0.78(0.72-0.84)$ & $<0.001$ & $<0.001$ & $<0.001$ \\
\hline $40-49$ & 1434 & 627 & 2357 & $0.58(0.54-0.62)$ & $0.15(0.13-0.16)$ & $2.33(2.18-2.55)$ & $<0.001$ & $<0.001$ & $<0.001$ \\
\hline$\geq 50$ & 2559 & 1091 & 2826 & $0.85(0.80-0.91)$ & $1.47(1.34-1.60)$ & $1.07(1.01-1.15)$ & $<0.001$ & $<0.001$ & 0.019 \\
\hline \multicolumn{10}{|l|}{$\begin{array}{l}\text { Vaginal } \\
\text { delivery }\end{array}$} \\
\hline $1-3$ & 1074 & 337 & 1014 & $1.13(1.03-1.23)$ & $0.95(0.84-1.08)$ & $0.90(0.83-0.98)$ & 0.006 & 0.45 & 0.027 \\
\hline$\geq 4$ & 5741 & 2012 & 6149 & $1.12(1.03-1.23)$ & $1.04(0.92-1.18)$ & $1.10(1.01-1.20)$ & 0.007 & 0.45 & 0.027 \\
\hline \multicolumn{10}{|l|}{$\begin{array}{l}\text { Maternal } \\
\text { delivery age }\end{array}$} \\
\hline $17-24$ & 4021 & 1057 & 4963 & $0.83(0.78-0.89)$ & $0.45(0.41-0.49)$ & 1.81 (1.69-1.93) & $<0.001$ & 0.51 & $<0.001$ \\
\hline $25-34$ & 1147 & 871 & 1977 & $0.47(0.43-0.51)$ & $2.04(1.86-2.24)$ & $1.34(1.25-1.44)$ & $<0.001$ & $<0.001$ & $<0.001$ \\
\hline$\geq 35$ & 1647 & 421 & 223 & $4.38(3.98-4.83)$ & $1.41(1.25-1.58)$ & $0.11(0.09-0.12)$ & $<0.001$ & $<0.001$ & $<0.001$ \\
\hline \multicolumn{10}{|l|}{$\begin{array}{l}\text { History } \\
\text { of surgery* }\end{array}$} \\
\hline Positive & 2341 & 1027 & 4897 & \multirow[t]{2}{*}{$0.31(0.29-0.33)$} & \multirow[t]{2}{*}{$0.72(0.66-0.79)$} & \multirow[t]{2}{*}{$3.71(3.48-3.97)$} & \multirow[t]{2}{*}{$<0.001$} & \multirow[t]{2}{*}{$<0.001$} & \multirow[t]{2}{*}{$<0.001$} \\
\hline Negative & 4474 & 1321 & 2266 & & & & & & \\
\hline \multicolumn{10}{|l|}{$\begin{array}{l}\text { Fetal birth } \\
\text { weight }\end{array}$} \\
\hline$<2500 \mathrm{~g}$ & 716 & 557 & 761 & $0.73(0.66-0.80)$ & $2.63(2.35-2.93)$ & $0.73(0.67-0.81)$ & $<0.001$ & $<0.001$ & $<0.001$ \\
\hline $2500-4000 \mathrm{~g}$ & 2897 & 1207 & 3118 & $0.88(0.83-0.94)$ & $1.39(1.28-1.52)$ & $0.73(0.67-0.81)$ & $<0.001$ & $<0.001$ & $<0.001$ \\
\hline$>4000 \mathrm{~g}$ & 3202 & 585 & 3284 & $1.29(1.21-1.37)$ & $0.38(0.34-0.42)$ & $1.17(1.10-1.24)$ & $<0.001$ & $<0.001$ & $<0.001$ \\
\hline \multicolumn{10}{|l|}{$\begin{array}{l}\text { Difficult } \\
\text { delivery history }\end{array}$} \\
\hline Positive & 4071 & 1712 & 4877 & \multirow[t]{2}{*}{$0.65(0.61-0.70)$} & \multirow[t]{2}{*}{$1.51(1.37-1.66)$} & \multirow[t]{2}{*}{$1.24(1.16-1.33)$} & \multirow[t]{2}{*}{$<0.001$} & \multirow[t]{2}{*}{$<0.001$} & \multirow[t]{2}{*}{$<0.001$} \\
\hline Negative & 2744 & 636 & 2276 & & & & & & \\
\hline \multicolumn{10}{|l|}{ BMI } \\
\hline $18.5-25$ & 937 & 391 & 719 & $1.20(1.09-1.32)$ & $1.48(1.31-1.67)$ & $0.65(0.59-0.72)$ & $<0.001$ & $<0.001$ & $<0.001$ \\
\hline $25-29.99$ & 1912 & 874 & 1473 & $1.19(1.10-1.27)$ & $1.85(1.69-2.03)$ & $0.59(0.55-0.63)$ & $<0.001$ & $<0.001$ & $<0.001$ \\
\hline$\geq 30$ & 3966 & 1084 & 4971 & $0.79(0.74-0.84)$ & $0.48(0.44-0.52)$ & 1.84 (1.73-1.97) & $<0.001$ & $<0.001$ & $<0.001$ \\
\hline
\end{tabular}

SUI - stress urinary incontinance, UUI - urge urinary incontinance, POP - pelvic organ prolapse, BMI - body mass index $\left(\mathrm{kg} / \mathrm{m}^{2}\right), \mathrm{OR}, \mathrm{SUI}$ odds ratio, $\mathrm{OR}_{2}$ - UUl odds ratio, $\mathrm{OR}_{3}-\mathrm{POP} d d$ s ratio. ${ }^{*}$ Except cesarean section or contraception surgery. A group of women belonging to the complementary category of an individual variable was a reference category for each of the variables

multiparous women $\left(\mathrm{OR}_{3}: 1.10\right.$ [CI: 1.01-1.20]), obese women $\left(\mathrm{OR}_{3}: 1.84\right.$ [CI: 1.73-1.97]), women with maternal age between 17-24 and 25-34 ( $\mathrm{OR}_{3}$ : 1.81 [CI: 1.691.93], $\mathrm{OR}_{3}: 1.34$ [CI: 1.25-1.44]), in women with a surgical history ( $\mathrm{OR}_{3}: 3.71$ [CI: 3.48-3.97]), women with a macrosomic baby birth history $\left(\mathrm{OR}_{3}: 1.17\right.$ [CI: 1.10$1.24])$, women with a difficult delivery history $\left(\mathrm{OR}_{3}: 1.24\right.$ [CI: 1.16-1.33]) (Table 2).

\section{DISCUSSION}

The increase in intra-abdominal pressure especially acts on the anterior pelvic floor. The pressure increase in the pelvic region should be supported by the mus- cle groups and ligaments that form the pelvic floor. A decrease in levator ani muscle and obturator muscle mass may lead to a decrease in support strength, prolapse and incontinence [14]. In women, estrogen receptors are dense in the pelvic floor muscles, bladder triangle, distal ureter squamous epithelium. With age, physiological changes occur at these levels with the reduction of estrogen [15]. Pelvic floor muscles are weakened and prolapsed to the level of the bladder, uterus and rectum, causing compression in these structures and the urethra position changes. Previous studies have shown that age is a risk factor for POP and UI and the prevalence of UI increases with age $[6,16,17]$. Similar to the studies in the 
literature, the risk of POP and UI in patients aged 40 and over was increased in this study.

Pregnancy and delivery can lead to weakening of the pelvic floor muscles, leading to impaired sphincter function and pelvic floor pathologies [18]. Multiparity and vaginal birth is reported to be the most important risk factors for PFD in an earlier study conducted among patients operated for POP and SUI in Turkey [3]. Similar to this study, there are many studies reporting that vaginal delivery and multiparity increase the risk of POP [4-6]. In yet another study conducted in Turkey; multiparous women $(\geq 4)$ has been shown to increase the risk [19]. In this study, multiparity has been identified as a risk factor for UUI and POP, and these data are compatible with previous studies.

Previous surgeries and musculoskeletal injuries; it can cause damage to lumbosacral nerves (such as genitofemoral, obturator, pudendal) or autonomic nerves (such as lower hypogastric plexus) [19]. In addition, postoperative adhesions can affect the sensitivity of peripheral neural structures and cause multiple pathophysiological changes [20]. In a recent study, it was reported that previous abdominal or pelvic surgeries were risk factors for PFD [21]. In this study, similar abdominal/pelvic surgery was found to be a risk factor for PFD. However, due to the nature of the cross-sectional study and the large population, the types of surgery could not be categorized.

Various studies have shown that the risk of developing UI increases in women with a history of macrosomic baby birth during the 5 -year period after delivery [22, 23]. In a study by Abrams et al. it was reported that UI prevalence increased in women with a macrosomic baby birth history [9]. In addition, it was stated in the studies that the macrosomic baby birth history is related to POP [24]. In this study, macrosomic baby birth history is a risk factor for the PDF.

The main underlying risk factors for PFD development are; direct and indirect injuries to all parts of the pelvic floor and levator ani muscle avulsion increases in women with a difficult delivery history [8]. In some studies, it has been reported that difficult delivery history increases the risk of POP $[25,26]$. In this study, the fact that difficult delivery history is a risk factor for UUI and POP supports the studies.

There are some studies stating that high BMI is a risk factor for POP $[6,19,27]$. In a cross-sectional study conducted in the Netherlands, overweight women (BMI > 25) prevalence was reported to increase in women with a history of POP and SUI surgery [28]. However, there are studies indicating that BMI height is not associated with POP $[3,4]$. In this study, high BMI was found as a risk factor for the whole PFD.

In a recent study examining the relationship between factors such as difficult delivery history, maternal age and BMI with PFD; maternal age increase has been shown to be the main factor for the development of UI and POP [8].
Another study has been shown in women with high maternal age ( $>35$ years) where difficult delivery is increased compared to young women $(<19$ years) [29]. In this study, the risk of UI increased with the increase of maternal age, but the risk of POP decreases. Earlier, another study conducted in Turkey, has increased the frequency of first marriage for women under the age of eighteen years old. This finding has been associated with adolescent pregnancy and multiparity [30]. In this study, the increase in multiparity and low maternal age in the POP group may be related to this data.

The study had its strengths. The first study is one of the most comprehensive studies done on a large rural population in Turkey. Secondly, the data were verified not only by the data recorded in the database, but also by interviews with patients. In addition, many risk factors for PFD have been examined separately for each group.

Our study had some limitations. Since our study was primarily a cross-sectional study, the data were analyzed retrospectively. Therefore, the results may be incomplete. This data was not investigated because the second cesarean section was not included in the study. Thirdly, the answers given to the questionnaire may cause bias.

\section{CONCLUSIONS}

SUI, UUI and POP were common in the rural Turkish population of women. Age, multiparity, early maternal age, difficult labor history, previous abdominal and pelvic surgery, macrosomic baby birth are risk factors for the development of PFD. These factors should be investigated in patients to prevent complications that may develop in the future, to treat symptoms and to alleviate the effect of PFD on quality of life.

\section{DISCLOSURE}

The authors report no conflict of interest.

\section{References}

1. Milsom I, Altman D, Lapitan MC, et al. Epidemiology of urinary (UI) and faecal (FI) incontinence and pelvic organ prolapse (POP) Paris: Health Publication Ltd. Available from: https://www.ics.org/publications/ici_4/files-book/comite-1. pdf (accessed: 17 June 2020).

2. Delancey JO, Kane Low L, Miller JM, et al. Graphic integration of causal factors of pelvic floor disorders: an integrated life span model. Am J Obstet Gynecol 2008; 199 (6): 610.e1-5.

3. Kurt S, Canda MT, Bal M, Tasyurt A. Are there any preventable risk factors for women who had surgery for Pelvic Organ Prolapse and stress Urinary Incontinence? Pak J Med Sci 2018; 34 (4): 874-878.

4. Glazener C, Elders A, Macarthur C, et al. Childbirth and prolapse: long-term associations with the symptoms and objective measurement of pelvic organ prolapse. BJOG 120 (2): 161-168.

5. Yeniel AO, Ergenoglu AM, Askar N, et al. How do delivery mode and parity affect pelvic organ prolapse? Acta Obstet Gynecol Scand 2013; 92 (7): 847-851. 
6. Whitcomb EL, Rortveit G, Brown JS, et al. Racial differences in pelvic organ prolapse. Obstet Gynecol 2009; 114 (6): 1271 1277.

7. Memon HU, Blomquist JL, Dietz HP, et al. Comparison of levator ani muscle avulsion injury after forceps-assisted and vacuum-assisted vaginal childbirth. Obstet Gynecol 2015; 125 (5): 1080-1087

8. Urbankova I, Grohregin K, Hanacek J, et al. The effect of the first vaginal birth on pelvic floor anatomy and dysfunction. Int Urogynecol J 2019; 30 (10): 1689-1696.

9. Abrams P, Cardozo L, Khoury S, Wein A. Incontinence fifth edition, the international consultation on urological diseases. Available from: http://www.icud.info/incontinence.html (accessed: 17 June 2020).

10. National Institutes of Health and the North American Association for the Study of Obesity. The Practical Guide: Identification, Evaluation, and Treatment of Overweight and Obesity in Adults. Washington, DC: U.S. Department of Health and Human Services. Available from: https://www.nhlbi.nih.gov/ files/docs/guidelines/prctgd_c.pdf (accessed: 17 June 2020).

11. Sandvik H, Hunskaar S, Vanvik A, et al. Diagnostic classification of female urinary incontinence: an epidemiological survey corrected for validity. J Clin Epidemiol 1995; 48 (3): 339-343.

12. Barber MD, Neubauer NL, Klein-Olarte V. Can we screen for pelvicorgan prolapse without a physical examination in epidemiologic studies?. Am J Obstet Gynecol 2006; 195 (4):942-948.

13. Persu C, Chapple CR, Cauni V, et al. Pelvic Organ Prolapse Quantification System (POP-Q) - a new era in pelvic prolapse staging. J Med Life 2011; 4 (1): 75-81.

14. Delancey J, Morgan D, Fenner D, et al. Comparison Of Levator Ani Muscle Defects And 351 Function İn Women With And Without Pelvic Organ Prolapse. Obstet Gynecol 2007; 109 (2 Pt 1): 295-302.

15. Blakeman PJ, Hilton P, Bulmer JN. Mapping estrogen and progesterone receptors throughout the female lower urinary tract. Neurourol Urodyn 1996; 15: 324-325.

16. Akkus Y, Pinar G. Evaluation of the prevalence, type, severity, and risk factors of urinary incontinence and its impact on quality of life among women in Turkey. Int Urogynecol J 2016; 27 (6): 887-893.

17. Kudish BI, Iglesia CB, Gutman RE, et al. Risk Factors for Prolapse Development in White, Black, and Hispanic Women. Female Pelvic Med Reconstr Surg 2011; 17 (2): 80-90.

18. Kocaöz S, Talas M, Atabekoğlu C. Urinary incontinence in pregnant women and their quality of life. J Clin Nurs 2010; 19 (23-24): 3314-3323.

19. Possover M, Lemos N. Risks, symptoms and management of pelvic nerve damage secondary to surgery for organ prolapse: a report of 95 cases. Int Urogynecol J 2011; 22 (12): 1485-1490.

20. Shacklock M. Clinical Neurodynamics: A New System of Musculoskeletal Treatment. Elsevier, Toronto, Canada 2005.

21. Chen CCG, Avondstondt AM, Khatry SK, et al. Prevalence of symptomatic urinary incontinence and pelvic organ prolapse among women in rural Nepal. Int Urogynecol J 2019; 31 (9): 1851-1858.
22. Özdemir E, Özerdoğan N, Ünsal A. Urinary incontinence, sexual dysfunction and quality of life among married women older than, in Ankara gulveren health clinic region. Turk Kiin J Gynecol Obst 2011; 21: 266-276.

23. Parazzini F, Colli E, Origgi G, et al. Risk factors for urinary incontinence in women. Eur Urol 2000; 37: 637-643.

24. Swift SE, Pound T, Dias JK. Case-control study of etiologic factors in the development of severe pelvic organ prolapse. Int Urogynecol J Pelvic Floor Dysfunct 2001; 12 (3): 187-192.

25. Mothes AR, Radosa MP, Hofmann AA, Runnebaum IB. Risk index for pelvic organ prolapse based on established individual risk factors. Arch Gynecol Obstet 2016; 293 (3): 617-624.

26. Norton PA, Allen-Brady K, Cannon-Albright LA. The familiarity of pelvic organ prolapse in the Utah population database. Int Urogynecol J 2013; 24 (3): 413-418.

27. Subki AH, Fakeeh MM, Hindi MM, et al. Fecal and Urinary Incontinence Associated with Pregnancy and Childbirth. Mater Sociomed 2019; 31 (3): 202-206.

28. de Boer TA, Slieker-Ten Hove MC, Burger CW, et al. The prevalence and factors associated with previous surgery for pelvic organ prolapse and/or urinary incontinence in a cross-sectional study in The Netherlands. Eur J Obstet Gynecol Reprod Biol 2011; 158 (2): 343-349.

29. Omih EE, Lindow S. Impact of maternal age on delivery outcomes following spontaneous labour at term. J Perinat Med 2016; 44 (7): 773-777.

30. Ozemir E, Ozerdogan N, Unsal A. Ankara Gülveren Sağlik Ocağı Bölgesi’nde 20 Yaş Üzeri Evli Kadınlarda Üriner İnkontinans, Cinsel Disfonksiyon ve Yaşam Kalitesi. Turkiye Klinikleri J Gynecol Obst 2011; 21 (4): 266-276.

\section{AUTHORS' CONTRIBUTIONS}

??? 